OPEN ACCESS

Edited by:

Abhay Satoskar:

The Ohio State University,

United States

Reviewed by:

Tamás Laskay,

University of Lübeck, Germany

James Alexander,

University of Strathclyde,

United Kingdom

Ranadhir Dey,

United States Food and Drug

Administration, United States

*Correspondence:

Fabienne Tacchini-Cottier Fabienne.Tacchini-Cottier@unil.ch

Specialty section

This article was submitted to Microbial Immunology,

a section of the journal

Frontiers in Immunology

Received: 04 January 2021 Accepted: 04 February 2021

Published: 01 March 2021

Citation:

Passelli $K$, Billion $O$ and Tacchini-Cottier F (2021) The Impact of Neutrophil Recruitment to the Skin on the Pathology Induced by Leishmania Infection.

Front. Immunol. 12:649348. doi: 10.3389/fimmu.2021.649348

\section{The Impact of Neutrophil Recruitment to the Skin on the Pathology Induced by Leishmania Infection}

\author{
Katiuska Passelli, Oaklyne Billion and Fabienne Tacchini-Cottier* \\ Department of Biochemistry, WHO Collaborative Centre for Research and Training in Immunology, University of Lausanne, \\ Lausanne, Switzerland
}

Leishmania (L.) are obligate intracellular protozoan parasites that cause the leishmaniases, a spectrum of neglected infectious vector-borne diseases with a broad range of clinical manifestations ranging from local cutaneous, to visceral forms of the diseases. The parasites are deposited in the mammalian skin during the blood meal of an infected female phlebotomine sand fly. The skin is a complex organ acting as the first line of physical and immune defense against pathogens. Insults to skin integrity, such as that occurring during insect feeding, induces the local secretion of pro-inflammatory molecules generating the rapid recruitment of neutrophils. At the site of infection, skin keratinocytes play a first role in host defense contributing to the recruitment of inflammatory cells to the infected dermis, of which neutrophils are the first recruited cells. Although neutrophils efficiently kill various pathogens including Leishmania, several Leishmania species have developed mechanisms to survive in these cells. In addition, through their rapid release of cytokines, neutrophils modulate the skin microenvironment at the site of infection, a process shaping the subsequent development of the adaptive immune response. Neutrophils may also be recruited later on in unhealing forms of cutaneous leishmaniasis and to the spleen and liver in visceral forms of the disease. Here, we will review the mechanisms involved in neutrophil recruitment to the skin following Leishmania infection focusing on the role of keratinocytes in this process. We will also discuss the distinct involvement of neutrophils in the outcome of leishmaniasis.

Keywords: skin, keratinocytes, wound healing, neutrophils, Leishmania, cutaneous leishmaniasis, visceral leishmaniasis, leishmaniasis

\section{THE LEISHMANIASES}

The Leishmaniases are a group of neglected vector-borne diseases caused by protozoan parasites belonging to the Leishmania (L.) genus. Parasites are deposited into the mammalian host skin during the blood meal of infected female phlebotomine sand flies. At least twenty different Leishmania species can infect humans causing three main clinical manifestations including cutaneous, mucocutaneous and visceral forms $(1,2)$. The outcome of the disease depends on the infecting species along with host factors. Cutaneous leishmaniasis (CL) is the most common form characterized by the appearance of a skin ulcer at the sand fly bite site, usually on exposed body parts. Although skin lesions are most of the time self-healing and localized, they can leave 
seriously disfiguring and disabling life-long scars (3). The frequency of self-healing lesions depends, amongst other factors, on the Leishmania species. For instance, more than $75 \%$ of lesions caused by L. mexicana and the $60-70 \%$ caused by L. major heal within 3 months. In contrast, lesions caused by other New World Leishmania spp. such as L. panamensis and L. braziliensis take longer to heal, with an average frequency of only 35 and $10 \%$ that, respectively, self-heal after 3 months (4). Disseminated forms of CL have also been observed, where CL can manifest as multiple non-ulcerative nodules disseminating to the entire body (5). Mucocutaneous leishmaniasis (MCL) is a major CL complication that can manifest days to years following the cutaneous lesion. There are between 0.4 and $20 \%$ of CL cases in Brazil and Bolivia, respectively (6). The most endemic area for MCL is Latin America, where it results from infection with L. braziliensis, L. panamensis, L. guyanensis, and L. amazonensis $(1,7)$. MCL develops when the parasites migrate from the localized skin lesion to mucosal tissues of the nose, mouth and throat cavities, through lymphatics and blood vessels. This can lead to massive destruction of the oral or nasal mucosa and potentially become life-threatening (8). Visceral leishmaniasis (VL) is the deadliest form of the disease resulting from parasite dissemination from the skin to visceral organs, such as the spleen and the liver. This leads to organ dysfunction, fever, weight loss, and is usually fatal if left untreated (9). Between 700,000 and 1 million new leishmaniasis cases are reported each year across 100 countries $(2,10)$. The disease predominantly affects poor populations living in precarious hygiene and housing conditions (2). Several efforts have been made in order to develop a vaccine, but no effective and safe vaccine to prevent human leishmaniasis is currently available (11). Several drugs are available to treat leishmaniasis but many of them present toxicity with severe side effects and low efficacy, correlating with frequent treatment interruptions promoting the development of drug resistance (12). Currently, resistance has been reported for most of the drugs in use. It is, therefore, crucial to gain a better understanding of the local immune response to Leishmania infection with the long-term goal to develop anti-leishmanial drugs, which are efficient, less toxic, easy to administrate and affordable for emerging countries (13).

\section{THE SKIN AND PARASITE ENTRY}

The skin acts as the first line of physical and immune defense against Leishmania parasites. The two main layers composing the skin are the epidermis and the dermis. The outer surface is the epidermis, characterized by overlapping layers of keratinocytes infiltrated by melanocytes. The dermis is composed of intermingled fibroblasts and extracellular matrix and is drained by blood and lymphatic vessels. The skin also includes a vast population of immune cells including Langerhans cells (skin resident dendritic cells), T lymphocytes and recruited inflammatory cells such as natural killers, macrophages, mast cells, dendritic and neutrophils, all of which participate to the immune defense against Leishmania infection (14).

Keratinocytes sense pathogens and initiate the inflammatory immune response. To do this, these epidermal cells possess several innate immune receptors able to sense invading microbes. These receptors include mostly Toll-like receptors (TLR), NODlike receptors (NLR), RIG-I-like receptors (RLR), and C-type lectin receptors (CLR). Notably, keratinocytes express TLR1, TLR2, TLR4, TLR5, TLR6, and TLR10 on their cell surface, and TLR3, and TLR9 on the endosomal surface (15-22). The activation of the TLR-signaling pathways in keratinocytes mediates the secretion of pro-inflammatory cytokines and chemokines, which are mainly involved in the activation of the Th1 immune response and the recruitment of myeloid cells, including neutrophils (23). In response to pathogens, the activation of these receptors in keratinocytes enables the secretion of innate immune mediators participating in the skin immune response. Notably, in humans, keratinocytes generate antimicrobial peptides, including $\beta$-defensins $(24,25)$ and cathelicidins $(26,27)$. In addition to the direct killing of bacteria, fungi and viruses, these antimicrobial peptides can activate leukocytes. Furthermore, keratinocytes are a source of chemotactic mediators and cytokines, that enable the recruitment and activation of immune cells in the skin. For example, epidermal cells contribute to the recruitment of neutrophils in response to CXCL1 and CXCL8 release $(28,29)$. Keratinocytes produce cytokines such as tumor necrosis factor (TNF)- $\alpha$, IL- $1 \alpha$, IL-1 $\beta$, IL-6, IL-18, and IL-10 (29). Keratinocytes can also recruit effector $\mathrm{T}$ cells, following the secretion of CXCL9, CXCL10, CXCL11, and CCL20 (29).

\section{LEISHMANIA DEPOSITION IN THE SKIN}

Phlebotomine sand flies probe the exposed skin several times to find vessels and create a blood pool from which they feed. During this process, Leishmania parasites are deposited and they get in contact with keratinocytes. Although Leishmania are not internalized by keratinocytes (30-33), the parasites have been observed to interact with these cells (33). Several studies demonstrated that, during Leishmania infection, keratinocytes secrete factors that modulate the immune response. Indeed, $L$. major phosphoglycans, some of the major surface glycans of the parasite, trigger TLR2 in non-hematopoietic cells including keratinocytes, promoting the release of chemokines essential for early neutrophil recruitment (33). Scorza et al. showed that, in response to $L$. infantum but not $L$. major, human keratinocytes upregulate the expression of pro-inflammatory cytokines such as IL-6, CXCL8, TNF $\alpha$, and IL-1 $\beta$. Conversely, IL4 expression was increased in keratinocytes exposed to $L$. major (32). The same study further showed that keratinocytes exposed to L. infantum released factors promoting parasite control in monocytes (32). In the same line, Ehrchen et al. showed an increased expression of cytokines and chemokines in mouse keratinocytes isolated from L. major-resistant but not susceptible mice (34). In visceral leishmaniasis patients, the expression of IL10 in keratinocytes correlated with increased pathogenesis (35). Finally, the apoptosis of keratinocytes in CL correlated with skin ulceration, a process which relies on the Fas/TRAIL apoptotic pathway (36-38). 
Notably, the study of Ehrchen et al. suggested that IL4 produced by keratinocytes promoted the development of a protective Th1 immune response in C57BL/6 mice infected with L. major (34). In order to assess whether the IL-4 secreted by keratinocytes acted in an autocrine manner, mice with specific deletion of the IL- $4 \mathrm{R} \alpha$ in keratinocytes were generated on the $\mathrm{C} 57 \mathrm{BL} / 6$ and $\mathrm{BALB} / \mathrm{c}$ genetic background, that are, respectively, resistant, or susceptible to $L$. major infection. C57BL/6 mice deficient for IL-4R $\alpha$ in keratinocytes were able to develop a Th1 immune response and to heal their lesions following $L$. major infection. These data indicated that, in C57BL/6 mice, IL4 signaling in keratinocytes is not required for the development of a protective Th1 immune response (39). In a similar manner, infection of BALB/c mice deficient for IL- $4 \mathrm{R} \alpha$ in keratinocytes developed non-healing lesions characterized by a Th2 immune response, which was similar to those developed in WT BALB/c mice (40). These results showed that autocrine stimulation of keratinocytes by IL- 4 is not involved in disease evolution following $L$. major infection.

The contribution of keratinocytes in the activation of antigenspecific $\mathrm{T}$ cells has also been reported. In this regard, studies documented that keratinocytes express MHCII, but are lacking the expression of CD80 and CD86 co-stimulatory molecules, that are essential for the priming of naïve T cells (41). Indeed, despite the ability of keratinocytes to support $\mathrm{T}$ cell proliferation, they fail to activate naïve $\mathrm{T}$ cells and they induce $\mathrm{T}$ cell anergy $(42,43)$. The expression of the costimulatory molecule B7.2 was shown to be downregulated in keratinocytes from resistant but not susceptible mice infected with L. major (31). More recent data have shown that keratinocytes can process antigens and present them to antigen-specific CD4 and CD8 T cells, leading to cytokine production (44). However, the role of these interactions during Leishmania infection remains to be investigated.

In the skin, a heterogeneous population of resident immune cells, maintains the homeostasis and is critical for host defense. In addition to the epidermal layer described above, insults to epidermis and dermis integrity lead to the recruitment of circulating immune cells including dendritic cells, $\mathrm{T}$ cells, natural killer cells, monocytes and neutrophils. Amongst these, neutrophils are the first cells massively recruited to the damaged skin. We shall focus on the importance of neutrophils in the response to infection.

\section{NEUTROPHILS AND LEISHMANIA}

\section{Neutrophil General Functions}

Neutrophils are the most abundant leukocytes in the human blood circulation. They can be rapidly recruited to sites of injury or infection and are major players in innate immune defense against various pathogens (45). At the site of infection, neutrophils phagocytose microorganisms and kill them using a variety of mechanisms. The cytoplasm of neutrophils is rich in pre-stored granules that contain microbicidal proteins that can be rapidly released in the phagosomes or into the local microenvironment in order to eliminate pathogens. Neutrophil activation also triggers a respiratory burst leading to the production of reactive oxygen species (ROS) that is toxic for microorganisms $(46,47)$. Moreover, neutrophils can extrude neutrophil extracellular traps (NETs), which are extracellular web-like fibers consisting of chromatin associated with antimicrobial granule proteins. NETs trap microorganisms, a process that reduces parasite spreading. They can also kill pathogens through their association with a high concentration of microbicidal components (48).

In addition to their primary killing functions, neutrophils are increasingly reported to play significant immunoregulatory roles. Indeed, they can secrete a vast repertoire of cytokines or chemokines that may impact on the recruitment and function of various cell types. Through interactions with other immune cells, neutrophils can also contribute to the orchestration of the adaptive immune response $(49,50)$.

Neutrophils are the first cells to be recruited when the skin barrier is injured. Their importance in limiting microbial dissemination is highlighted by the predisposition of patients with neutropenia, or defective neutrophils, to harbor severe bacterial, parasitic or invasive fungal infections $(51,52)$. In contrast to these protective functions, neutrophils can also induce important tissue damage and inflammation that need to be tightly controlled (53). Deregulated neutrophil function is a feature of a heterogeneous group of skin pathologies named neutrophilic dermatosis (ND). These are conditions characterized by a wide spectrum of cutaneous lesions due to accumulation of neutrophils in the skin. ND are mainly caused by genetic mutations leading to excessive activity or production of inflammatory meditators involved in neutrophil recruitment and activation $(54,55)$.

Neutrophils are also major players engaged upon tissue injury and they also actively contribute to wound healing. However, neutrophils can also exert a negative impact on wound healing in some contexts. They can for instance contribute to the development of non-healing diabetic wounds. It was demonstrated that diabetes primes neutrophils to produce NETs, which impair healthy tissue healing $(56,57)$. Neutrophils were also recently shown to contribute to the pathogenesis of leprosy, a process contributing to the formation of skin lesions and lesions of peripheral nerves observed in this disease (58).

\section{THE MECHANISMS INVOLVED IN EARLY NEUTROPHIL RECRUITMENT TO THE SKIN FOLLOWING LEISHMANIA INFECTION}

Neutrophils are rapidly recruited to the site of Leishmania inoculation during infection. The infiltration of these cells is regulated by intertwined mechanisms related to the initial skin tissue damage caused by sand flies probing for blood (59). Several studies using experimental mouse models have shown that neutrophils are recruited following natural infection with sand flies (60-62) and that several factors contribute to this process. These include salivary gland components and the promastigote secretory gel that is synthesized by Leishmania in the sand fly (63-65). Furthermore, recent data showed that sand fly gut bacteria induce IL- $1 \beta$ secretion, a cytokine that also contributes 
to the recruitment of neutrophils (62). Of note, neutrophil recruitment to the site of infection following natural infection is more sustained compared to intradermal inoculation of parasites by needle injection $(60,61)$.

Neutrophils were similarly observed to be rapidly recruited when Leishmania are needle inoculated in mice (33, 60, 66-75). Phosphate buffer saline (PBS) or parasite injection promoted similar neutrophil recruitment during the first hour of injection, however, already $2 \mathrm{~h}$ after L. major or L. mexicana infection, the neutrophil infiltration became parasite-dependent $(60,71,74)$. In experimental models of CL, a relatively high dose of Leishmania has been commonly injected either subcutaneously (s.c) in the footpad (66-68), or in more recent studies intradermally (i.d.) in the ear $(33,60,69-75)$. Since the sand fly deposits the parasite in the host dermis, i.d. inoculation into the skin is closer to the natural infection and injection of a low dose of parasites $\left(10^{3}\right.$ or $10^{4}$ ) would be more related to the parasite load transmitted in natural infection (76). Interestingly, differences in neutrophil recruitment were observed depending on the site of infection. Intradermal injection led to a higher infiltration of neutrophils compared to s.c injection, while monocytes were more rapidly recruited following s.c. infection, indicating a site-dependent recruitment of myeloid cells in the skin $(75,77)$. Although most of the sand flies transmit a low dose of Leishmania parasites, needle injection of at least $10^{5}$ Leishmania is required to promote rapid parasite-dependent recruitment of neutrophils $(70,74,76)$, further revealing the importance of sand fly derived components in the recruitment of these cells. Recently, it has been reported that depending on the distance of parasite deposition to the bite site, the predominant cells to contain parasites can be either neutrophils or dermal macrophages (78).

The group of Laskay first proposed that Leishmania parasites are silently transmitted to macrophages following phagocytosis of apoptotic and infected neutrophils in a model called the "Trojan Horse." This way of entry promotes the persistence of the parasites and their subsequent propagation in the host $(79,80)$. This model was recently validated in vivo and few dermal macrophages were visualized acquiring parasites through phagocytosis of apoptotic and parasitized neutrophils. In the same context, depletion of neutrophils before the infection reduced the number of infected dermal macrophages (78).

In mice, the recruitment of neutrophils to the site of infection following sand fly bite, or needle injection of a high dose of parasites, was shown to be bimodal, with a first rapid wave peaking during the first day post-infection (p.i), returning to basal levels by the second or third day p.i. $(33,61,67,69-71$, $73,74)$. A second wave of neutrophils occurring approximately 1 week post $L$. major infection was also observed, at a time that correlates with the appearance of the lesion (71). Following L. panamensis infection, the second peak of neutrophils was observed several weeks p.i and was shown to be significantly stronger than the first one (81). A second wave of neutrophils was also shown to infiltrate the skin tissue 7 weeks post L. major infection (82), 5 weeks post-L. major co-infection with lymphocytic choriomeningitis virus (LCMV) (83), and neutrophils were observed in the skin of unhealing chronic
L. mexicana lesions (84). The timing of the second wave of neutrophils is thus well documented and its timing likely varies depending on the virulence of the parasites, the parasite dose injected as well as the Leishmania spp.

In line with these studies, amastigotes were shown to infect both human and mouse neutrophils (84-86). Furthermore, following L. mexicana infection, not only are lesional neutrophils heavily infected, but a subset of neutrophils was shown to be permissive for parasite replication, suggesting that neutrophils may also serve as a replicating niche and/or safe temporary host target in chronic infection (84). Of interest, L. major amastigotes were not observed to replicate in C57BL/6 neutrophils (75), a difference likely linked to the distinct formation of a parasitophorous vacuole and/or to differences in the composition of the parasite surface in the two Leishmania spp.

Several skin chemotactic factors are responsible for the recruitment of neutrophils following Leishmania infection. For instance, the chemokines CXCL1 (KC) and CXCL2 (MIP-2) in mice and CXCL8 (IL-8) in humans, granulocyte chemotactic protein 2 (GCP-2/CXCL6) in mice and the cleaved complement C3 were all shown to promote neutrophil recruitment $(59,87-$ 89). Additionally, during the second wave of neutrophils, IL-17 also contributes to their recruitment (90).

\section{EFFECTOR FUNCTION OF NEUTROPHILS DURING LEISHMANIASIS}

Although neutrophils possess an arsenal of mechanisms to kill infecting pathogens, some species of Leishmania can survive inside these cells and use them as a safe shelter while some others are killed by neutrophils (74, 84, 86, 91-96). The mechanisms involved in parasite escape in neutrophils will not be discussed as they have been recently reviewed (97), but we will discuss the impact of neutrophil presence on the Leishmaniainduced pathology.

The impact of neutrophils on the development of leishmaniasis has been observed to be either protective or detrimental depending on the infecting Leishmania species and the host genetics and immune system (Figure 1). Most of the current knowledge acquired related to the impact of neutrophils in experimental Leishmania infection has been obtained either following mAb-induced neutrophil depletion at the onset of infection or using genetically neutropenic mice $(60,67,70,72,74,82,98-100)$. In order to transiently deplete neutrophils in mice, three monoclonal antibodies have been used, each of them with some limitations. Several studies have used the RB6-8RC5 monoclonal antibody that recognizes the Gr1 epitope which is common between cells expressing Ly6G and Ly6C (101). The RB6-8RC5 antibody efficiently depletes neutrophils and inflammatory monocytes (77). The NIMP-R14 mAb depletes neutrophils and also a subset of inflammatory monocytes $(77,102)$. Finally, the $1 \mathrm{~A} 8$ monoclonal antibody targets specifically Ly6G that is expressed exclusively in neutrophils (103) but depletion is transient, and if used for more than a week, an increased release of neutrophils from the $\mathrm{BM}$ is observed. Differences in mAb isotypes also results in 
different depletion efficacy. Novel mAb administration strategies may circumvent this problem (104). One thus has to be critical in evaluating studies using only $\mathrm{mAb}$ depletion strategies. Complementary approaches abolishing or reducing the presence of neutrophils are needed to better understand the implications of these cells in the outcome of infection. Nevertheless, compiling results obtained with these different approaches completed by in vitro studies in human neutrophils allowed us to shed a new light on the importance of these cells in Leishmania pathogenicity, with either protective or pathogenic roles (Table 1).

\section{PROTECTIVE ROLE FOR NEUTROPHILS IN LEISHMANIASIS}

The first evidence suggesting a positive role of neutrophils during Leishmania infection was suggested in mice infected with the Bokkara strain of L. major. C57BL/6 mice depleted of neutrophils and monocytes (RB6-8RC5 antibody) at $-3,0$ and 3 days post infection, and infected s.c. with $10^{7}$ L. major, showed increased lesion size and a higher parasite burden (98). Similarly, depletion of neutrophils using the NIMP-R14 antibody in C57BL/6 mice promoted the development of a more prominent lesion during the first weeks following L. major LV39 infection, but the lesion eventually healed (67). BALB/c mice infected with $L$. major Bokkara and depletion of neutrophils using the RB6-8RC5 antibody, showed increased lesion progression during the first 6 weeks post infection, without affecting the chronic progression of the disease (98). These latter results contrasted with other data (see below), and these differences might be explained by the distinct species or strains of parasite inoculated, different dose of parasite injected and the specificity of the antibodies used to deplete neutrophils.

Neutrophils were further reported to secrete CCL3, a chemokine that contributes to the recruitment of dendritic cells (DC) to the site of L. major infection in C57BL/6 mice, a process shown to contribute to the development of a protective immune response (69). In contrast, apoptotic neutrophils containing live Leishmania were shown to be uptaken by dermal dendritic cells, a process inhibiting the development of an adaptive immune response (71). These data further demonstrated a complex role for neutrophils in self-healing experimental CL. In addition, the sensing of $L$. major by neutrophil endosomal TLR7, was shown to be critical for the early regulation of parasite burden and subsequent disease control in L. major LV39 infected C57BL/6 mice (75).

The presence of neutrophils was also shown to be protective during the first week post-infection in BALB/c mice infected with $L$. amazonensis in a study using the RB6-8RC5 antibody to deplete neutrophils (72). L. amazonensis promastigotes were efficiently killed by neutrophils in vitro, whereas the amastigote form of the parasite resisted neutrophil killing (86), suggesting that neutrophils may have a distinct role early post-infection than during the chronic phase of the disease. In addition, following infection of mice with $L$. amazonensis, neutrophil programmed cell death was altered due to genetic defective ROS production, and pathology was shown to be associated with the presence of necrotic neutrophils, suggesting that appropriated neutrophil programmed cell death is essential for the control of L. amazonensis-induced dermal lesions (105). Similarly, the presence of neutrophils co-cultured in vitro with macrophages reduced $L$. amazonensis burden in macrophages (106). The depletion of neutrophils using the RB6-8RC5 antibody in BALB/c mice infected with L. braziliensis, also promoted the development of a more prominent lesion with increased parasite burden during the first 2 weeks post-infection (100). Moreover, Carlsen et al. showed that the internalization of L. braziliensis amastigotes by neutrophils induced a strong activation of these cells, leading to efficient killing of the parasite (107). Collectively, these data show that neutrophils are efficient in controlling the parasites following infection with these Leishmania spp.

Neutrophils were also shown to play a protective role following needle injection of $L$. donovani and L. infantum, two Leishmania spp. causing visceral leishmaniasis (VL). The infection of neutrophil-depleted C57BL/6 mice with L. donovani resulted in a hepatosplenomegaly and a higher parasite burden in the spleen and liver compared to neutrophil-sufficient mice. In this study, the RB6-8RC5 antibody was used for depletion purposes (108). In the same vein, neutrophils contributed to the development of a protective immune response during L. donovani infection of $\mathrm{BALB} / \mathrm{c}$ mice. In this latter study, neutropenic mice had a splenomegaly with a higher parasite load in the spleen and bone marrow. This phenotype was associated with increased IL-4 and IL-10 secretion and reduced IFN- $\gamma$ levels in the spleen whereby the NIMP-R14 antibody was used to deplete neutrophils (109). Additionally, using the RB6-8C5 depleting antibody, neutrophils were also shown to contribute to the early control of infection in $\mathrm{BALB} / \mathrm{c}$ mice infected with L. infantum $(70,110)$. During L. infantum infection, TLR2 and TLR9 were shown to be critical for the recruitment of neutrophils to the inflammatory site, contributing to the control of infection $(111,112)$. Collectively, these studies show that, although the $\mathrm{mAb}$ used for neutrophil depletion was not always specific for neutrophils, neutrophils can play their well-known protective role in CL and VL.

\section{A DETRIMENTAL ROLE FOR NEUTROPHILS DURING LEISHMANIASIS}

The contribution of neutrophils in the development of a nonprotective immunity was first reported using the classical $L$. major s.c. infection in BALB/c mice, that develop Th2 immune response correlating with the development of unhealing skin lesions. The transient depletion of neutrophils at the onset of infection in BALB/c mice, using the NIMP-R14 antibody, allowed better resolution of skin lesions and parasite burden, than mice injected with a control $\mathrm{mAb}$, a process correlating with a decreased Th2 immune response (67). In addition, using the RB6-8RC5 antibody, Ribeiro-Gomes et al., also showed that neutrophil depletion reduced the parasite burden in L. majorinfected BALB/c mice (99). Th17 cells secrete IL-17, a cytokine which recruits neutrophils. Following L. major infection, this 


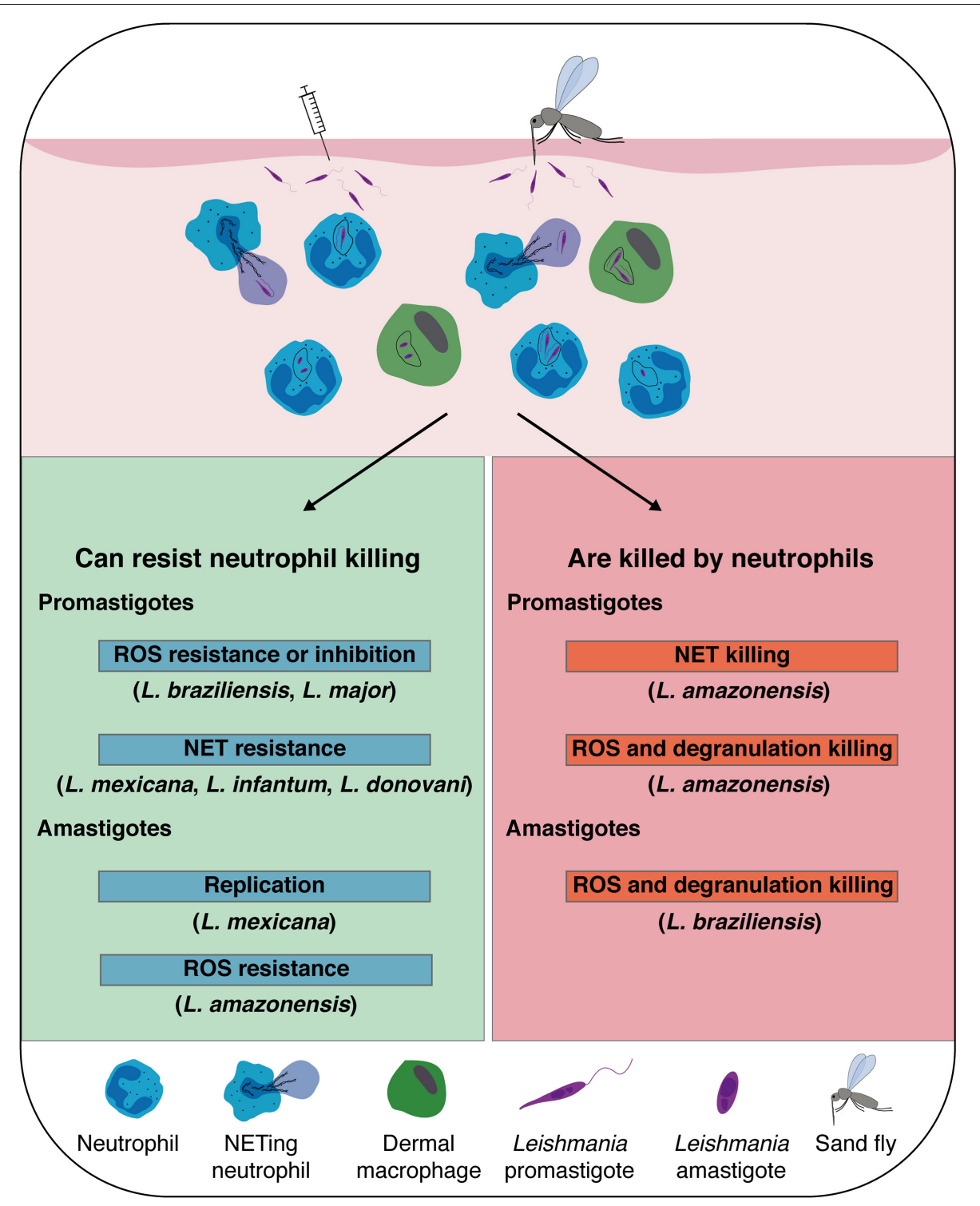

FIGURE 1 | Leishmania spp. that are susceptible, or that escape neutrophil killing: Leishmania inoculation in the host dermis by natural sand fly bite, or experimental needle injection, promotes a rapid recruitment of neutrophils, which sequestrate the parasite by phagocytosis or release of neutrophil extracellular traps (NETs). In addition to neutrophils, dermal macrophages are also heavily infected early post-infection contributing to the establishment of the infection. Although neutrophil killing mechanisms efficiently eliminate some spp. of Leishmania promastigotes and amastigotes, some Leishmania developed mechanisms to resist or inhibit reactive oxygen species (ROS) formation and survive inside neutrophils and NETs. Notably, L. mexicana amastigotes were shown to replicate inside neutrophils.

IL-17-induced neutrophil recruitment was shown to promote CL pathogenicity in infected BALB/c mice (90).

Neutrophil recruitment to the skin also contributed to the severe pathology associated with infection with a low dose of $L$. major Seidman, a parasite that causes severe disease in C57BL/6 mice despite the development of a strong Th1 immune response $(82,113)$. Neutropenic Genista mice infected with L. major Seidman developed a healing lesion associated with a decreased parasite burden and an increased protective Th1 immune response, further emphasizing the role of neutrophils in influencing the adaptive immune response (82). Of note, the negative role of neutrophils was associated with the activation of the NLRP3 inflammasome and the subsequent secretion of IL$1 \beta$ (82). Using a different approach, we recently showed that the recruitment of neutrophils induced by L. major-triggered TLR2 activation in non-hematopoietic cells, delayed the control of the disease in C57BL/6 mice infected with L. major LV39 (33).

Neutrophils contribute to the chronicity of $L$. mexicana disease in C57BL/6 mice and also play a negative role in the disease. This was demonstrated using mice either genetically neutropenic or depleted of neutrophils during the first days of infection after injection of the Ly6G mAb (74). Following 
TABLE 1 | Protective and detrimental role of neutrophils during Leishmania infection: Neutrophils play protective (resolution of the disease), or detrimental (enhanced disease) roles in cutaneous and visceral leishmaniasis depending on the infecting Leishmania spp., the genetic background of the host, the mode of infection and the host immune response.

\begin{tabular}{|c|c|c|c|c|c|}
\hline \multirow{2}{*}{$\begin{array}{l}\text { Role of neutrophils in } \\
\text { infection }\end{array}$} & \multicolumn{2}{|c|}{ Leishmania } & \multirow[t]{2}{*}{ Source of neutrophils } & \multirow[t]{2}{*}{ Route of infection } & \multirow[t]{2}{*}{ References } \\
\hline & species & strain & & & \\
\hline \multirow[t]{9}{*}{ Protective } & L. major & Bokkara & C57BL/6, BALB/c & S.c. ${ }^{a}$ & (98) \\
\hline & & LV39 & C57BL/6 & s.c. & $(67,99)$ \\
\hline & & LV39 & C57BL/6 & i.d. ${ }^{b}$ & $(69,75)$ \\
\hline & L. amazonensis & & BALB/c, C57BL/6 & i.d. & $(72,105)$ \\
\hline & L. amazonensis & & $\begin{array}{c}\text { BALB/c (Promastigote } \\
\text { and amastigote } \\
\text { parasites) } \\
\text { C57BL/6, C3H/HePas, } \\
\text { C3H/HeJ } \\
\text { (promastigote parasites) }\end{array}$ & in vitro & $(86,106)$ \\
\hline & L. amazonensis & & Human & in vitro & $(93,115,116)$ \\
\hline & L. braziliensis & & BALB/c & i.d. & $(100)$ \\
\hline & L. braziliensis & & C57BL/6 & in vitro & $(73,107)$ \\
\hline & $\begin{array}{l}\text { L. donovani } \\
\text { L. infantum }\end{array}$ & & $\begin{array}{l}\text { C57BL/6, BALB/c } \\
\text { C57BL/6, BALB/c }\end{array}$ & $\begin{array}{l}\text { i.v. } \\
\text { i.v. or i.d. }\end{array}$ & $\begin{array}{c}(108,109) \\
(70,110-112)\end{array}$ \\
\hline \multirow[t]{14}{*}{ Detrimental } & L. major & LV39 & BALB/c & s.c. & $(67,99)$ \\
\hline & & LV39 & C57BL/6 & i.d. & (33) \\
\hline & & IL81 & Human & in vitro & (79) \\
\hline & & $5 \mathrm{ASKH}$ & BALB/c & S.c. & (88) \\
\hline & & Friedlin & $\begin{array}{l}\text { C57BL/6 (LCMV } \\
\text { coinfection) }\end{array}$ & i.d. & (83) \\
\hline & & Friedlin & C57BL/6 & i.d. (sand fly) & $(60,61)$ \\
\hline & & Friedlin & BALB/c & i.d & (90) \\
\hline & & Seidman & C57BL/6 & i.d. & (82) \\
\hline & & Ryan & C57BL/6 & $\begin{array}{l}\text { i.d. (sand fly and } \\
\text { needle) }\end{array}$ & (78) \\
\hline & L. mexicana & & C57BL/6, BALB/c & i.d. & $(74,114)$ \\
\hline & L. mexicana & & C57BL/6 & i.d and in vitro & (84) \\
\hline & L. amazonensis & & $\begin{array}{c}\text { C57BL/6 (amastigote } \\
\text { parasites) }\end{array}$ & in vitro & (86) \\
\hline & L. panamensis & & Human & ex vivo & (118) \\
\hline & L. donovani & & $\mathrm{BALB} / \mathrm{c}$ & i.d. (sand fly) & (62) \\
\hline
\end{tabular}

as.c.: subcutaneous in the footpad.

${ }^{b}$ i.d.: intradermal in the ear.

ci.v.: intravenous.

Light gray: CL; dark gray: VL. Parasites are needle injected. When parasites are deposited following natural infection, "sand fly" is indicated.

i.d. infection with L. mexicana, neutropenic mice developed a small lesion that ultimately healed, in contrast to neutrophil sufficient mice that showed a persistent unhealing lesion. In addition, healing was shown to correlate with the development of a protective Th1 response and a decreased parasite burden (74). Furthermore, crosstalk between Th17 cells and neutrophils was shown to contribute to the enhanced susceptibility toward a chronic disease following L. mexicana infection in BALB/c mice (114). These studies further strengthen the role of neutrophils on the developing adaptive immune response. An important number of neutrophils has also been reported following coinfection of mice with L. major and LCMV and the development of chronic lesions highly infiltrated with neutrophils, correlated with the development of a more prominent lesion (83).

Finally, natural infection with L. major infected sand flies also showed that neutrophils contribute to the cutaneous pathology (60). Recently, the microbiota of sand flies was shown to be associated with neutrophil recruitment to the site of $L$. donovani infection. Treating the sand flies with antibiotics decreased neutrophil recruitment and impaired parasite visceralization, suggesting a pathological role for neutrophils in this model of infection (62). Of note these data contrast with the protective role for neutrophils in VL observed following needle injection of a high dose of parasites. 
Collectively these studies suggest that, to firmly assign a role for neutrophils in Leishmania infection, several parameters need to be taken into account including the dose of infection, the site of parasite injection, the mode of parasite delivery, the genetic background and immune status of the host as well as the neutropenic model used.

\section{NEUTROPHILS IN HUMAN LEISHMANIASIS}

To understand the role of neutrophils upon Leishmania infection, mouse models have predominantly been used but an increasing number of studies has been performed using peripheral blood neutrophils in vitro or ex vivo and using transcriptomics studies of infected skin biopsies. Results from these studies also suggest a dual role for neutrophils in human leishmaniasis, that can also be beneficial or detrimental depending on the infecting Leishmania species.

\section{PROTECTIVE ROLE OF HUMAN NEUTROPHILS DURING LEISHMANIA INFECTION}

Human neutrophils infected in vitro with $L$. amazonensis were reported to be activated and to produce ROS. Moreover, infected human neutrophils were shown to produce leukotriene B4 (LTB4), which promotes neutrophil degranulation and the killing of the parasite (115). Neutrophil degranulation in response to L. amazonensis was further shown to promote the killing of the parasite in infected macrophages (116).

\section{DELETERIOUS ROLE OF HUMAN NEUTROPHILS DURING LEISHMANIA INFECTION}

The transcriptional profile of primary human macrophages infected in vitro with L. (Vianna) panamensis, causing tegumentary leishmaniasis, differed significantly in response to infection depending on whether infection was undertaken with parasites isolated from self-healing patients or those showing chronic disease. Interestingly, expression levels of neutrophil-recruiting chemokines were predominantly observed in the transcriptomics analysis of macrophages infected with parasites isolated from chronic lesions, suggesting that the presence of neutrophils likely contributes to the sustained inflammation observed in chronic dermal leishmaniasis (117). In addition, performing transcriptomics of infected skin biopsies of patients that cured or failed to heal after meglumine antimoniate treatment, further showed that downregulation of the neutrophil activation genes was linked to cure of the disease, further supporting a deleterious role for neutrophils in chronic forms of the disease (118).

Neutrophils have been detected in patients with active cutaneous lesions of American tegumentary leishmaniasis from L. braziliensis patients (119-121). Neutrophils isolated from disseminated leishmaniasis patients infected with L. brazililensis were shown to be less activated and may thus contribute to parasite survival and dissemination (122).

In patients with active VL the number of circulating blood neutrophils was reduced and a considerable proportion of these blood peripheral cells was immature (123). Furthermore, neutrophils from VL patients were shown to be activated but to display impaired effector functions, suggesting that during active disease, neutrophils may contribute to the immunosuppression observed in VL patients $(123,124)$. Saliva components from the sand fly vector were shown to induce IL-17-induced neutrophil recruitment, a process favoring $L$. infantum infection (125) revealing, as was previously shown in murine models, an important role for this cytokine in neutrophil recruitment.

\section{CONCLUSION AND PERSPECTIVES}

Neutrophils are rapidly recruited to the skin following Leishmania infection and they play a critical role in phagocytosing the parasites and in shaping the immune response. In addition, neutrophils are also present in established lesions and were shown to contribute to parasite persistence. The impact of neutrophils on the development of leishmaniasis can be either protective, or detrimental, depending on a range of intricate factors including the infecting Leishmania spp., the host genetic background and immune response, as well as the local microenvironment induced by the parasite inoculation into the skin. In the last decade, keratinocytes have been identified as important cells for the modulation of the immune response following Leishmania infection, including neutrophil recruitment, further highlighting the importance of skin resident cells in the response against infection.

Many questions on the mechanism of action of neutrophils in leishmaniasis remain open. These include the understanding of the interactions between neutrophils and mast cells at the site of infection, the mechanisms involved in neutrophil recruitment to the draining lymphoid organs following infection and the interactions taking place between neutrophils and other recruited and resident cells in these organs. Further studies will help to identify potential targets for the treatment of leishmaniasis, in which neutrophils are contributing to the severity of the disease.

\section{AUTHOR CONTRIBUTIONS}

$\mathrm{KP}$ and FT-C wrote the review. OB, KP, and FT-C contributed to the figure and the table. All authors gave input on the review.

\section{ACKNOWLEDGMENTS}

We thank Drs. Miriam Diaz Varela and Borja Prat Luri and for critical reading of the manuscript and we acknowledge the financial support of the Swiss National Foundation for Scientific Research (310030_184751/1 to FT-C). 


\section{REFERENCES}

1. Pace D. Leishmaniasis. J Infect. (2014) 69:S108. doi: $10.1016 /$ j.jinf.2014.07.016

2. WHO (2020). Available online at: who.int/leishmaniasis/en/

3. Ameen M. Cutaneous leishmaniasis: advances in disease pathogenesis, diagnostics and therapeutics. Clin Exp Dermatol. (2010) 35:699-705. doi: 10.1111/j.1365-2230.2010.03851.x

4. Murray HW, Berman JD, Davies CR, Saravia NG. Advances in leishmaniasis. Lancet. (2005) 366:1561-77. doi: 10.1016/S0140-6736(05)67629-5

5. Burza S, Croft SL, Boelaert M. Leishmaniasis. Lancet. (2018) 392:95170. doi: 10.1016/S0140-6736(18)31204-2

6. Goto H, Lindoso JA. Current diagnosis and treatment of cutaneous and mucocutaneous leishmaniasis. Expert Rev Anti Infect Ther. (2010) 8:41933. doi: $10.1586 /$ eri.10.19

7. Sakthianandeswaren A, Foote SJ, Handman E. The role of host genetics in leishmaniasis. Trends Parasitol. (2009) 25:38391. doi: 10.1016/j.pt.2009.05.004

8. Reithinger R, Dujardin J-C, Louzir H, Pirmez C, Alexander B, Brooker S. Cutaneous leishmaniasis. Lancet Infect Dis. (2007) 7:581-96. doi: 10.1016/S1473-3099(07)70209-8

9. Chappuis F, Sundar S, Hailu A, Ghalib H, Rijal S, Peeling RW, et al. Visceral leishmaniasis: what are the needs for diagnosis, treatment and control? Nat Rev Microbiol. (2007) 5:873-82. doi: 10.1038/nrmicro1748

10. Alvar J, Vélez ID, Bern C, Herrero M, Desjeux P, Cano J, et al. Leishmaniasis worldwide and global estimates of its incidence. PLOS ONE. (2012) 7:e35671. doi: 10.1371/journal.pone.0035671

11. Singh B, Sundar S. Leishmaniasis: vaccine candidates and perspectives. Vaccine. (2012) 30:3834-42. doi: 10.1016/j.vaccine.2012.03.068

12. Bekhit AA, El-Agroudy E, Helmy A, Ibrahim TM, Shavandi A, Bekhit AEA. Leishmania treatment and prevention: natural and synthesized drugs. Eur J Med Chem. (2018) 160:229-44. doi: 10.1016/j.ejmech.2018.10.022

13. Croft SL, Sundar S, Fairlamb AH. Drug resistance in leishmaniasis. Clin Microbiol Rev. (2006) 19:111-26. doi: 10.1128/CMR.19.1.111-126.2006

14. Scott P, Novais FO. Cutaneous leishmaniasis: immune responses in protection and pathogenesis. Nat Rev Immunol. (2016) 16:581-92. doi: 10.1038/nri.2016.72

15. Kawai K, Shimura H, Minagawa M, Ito A, Tomiyama K, Ito M. Expression of functional Toll-like receptor 2 on human epidermal keratinocytes. $J$ Dermatol Sci. (2002) 30:185-94. doi: 10.1016/S0923-1811(02)00105-6

16. Song PI, Park YM, Abraham T, Harten B, Zivony A, Neparidze N, et al. Human keratinocytes express functional CD14 and Toll-like receptor 4. J Invest Dermatol. (2002) 119:424-32. doi: 10.1046/j.1523-1747.2002.01847.x

17. Baker BS, Ovigne JM, Powles AV, Corcoran S, Fry L. Normal keratinocytes express Toll-like receptors (TLRs) 1, 2 and 5: modulation of TLR expression in chronic plaque psoriasis. Br J Dermatol. (2003) 148:6709. doi: 10.1046/j.1365-2133.2003.05287.x

18. Mempel M, Voelcker V, Köllisch G, Plank C, Rad R, Gerhard M, et al. Toll-like receptor expression in human keratinocytes: nuclear factor kappaB controlled gene activation by Staphylococcus aureus is Toll-like receptor 2 but not Toll-like receptor 4 or platelet activating factor receptor dependent. $J$ Invest Dermatol. (2003) 121:1389-96. doi: 10.1111/j.1523-1747.2003.12630.x

19. Pivarcsi A, Bodai L, Réthi B, Kenderessy-Szabó A, Koreck A, Széll M, et al. Expression and function of Toll-like receptors 2 and 4 in human keratinocytes. Int Immunol. (2003) 15:721-30. doi: 10.1093/intimm/dxg068

20. Miller LS, Sørensen OE, Liu PT, Jalian HR, Eshtiaghpour D, Behmanesh BE, et al. TGF-alpha regulates TLR expression and function on epidermal keratinocytes. J Immunol. (2005) 174:6137-43. doi: 10.4049/jimmunol.174.10.6137

21. Köllisch G, Kalali BN, Voelcker V, Wallich R, Behrendt H, Ring J, et al. Various members of the Toll-like receptor family contribute to the innate immune response of human epidermal keratinocytes. Immunology. (2005) 114:531-41. doi: 10.1111/j.1365-2567.2005.02122.x

22. Lebre MC, van der Aar AM, van Baarsen L, van Capel TM, Schuitemaker $\mathrm{JH}$, Kapsenberg ML, et al. Human keratinocytes express functional Toll-like receptor 3, 4, 5, and 9. J Invest Dermatol. (2007) 127:33141. doi: $10.1038 /$ sj.jid. 5700530
23. Miller LS, Modlin RL. Human keratinocyte Toll-like receptors promote distinct immune responses. J Invest Dermatol. (2007) 127:262-3. doi: 10.1038/sj.jid.5700559

24. Harder J, Bartels J, Christophers E, Schroder JM. Isolation and characterization of human beta -defensin-3, a novel human inducible peptide antibiotic. J Biol Chem. (2001) 276:5707-13. doi: 10.1074/jbc.M008557200

25. Liu L, Roberts AA, Ganz T. By IL-1 signaling, monocytederived cells dramatically enhance the epidermal antimicrobial response to lipopolysaccharide. J Immunol. (2003) 170:57580. doi: 10.4049/jimmunol.170.1.575

26. Frohm M, Agerberth B, Ahangari G, Stâhle-Bäckdahl M, Lidén S, Wigzell $\mathrm{H}$, et al. The expression of the gene coding for the antibacterial peptide LL37 is induced in human keratinocytes during inflammatory disorders. J Biol Chem. (1997) 272:15258-63. doi: 10.1074/jbc.272.24.15258

27. Dorschner RA, Pestonjamasp VK, Tamakuwala S, Ohtake T, Rudisill J, Nizet $\mathrm{V}$, et al. Cutaneous injury induces the release of cathelicidin anti-microbial peptides active against group A Streptococcus. J Invest Dermatol. (2001) 117:91-7. doi: 10.1046/j.1523-1747.2001.01340.x

28. O’Toole EA, Mak LL, Guitart J, Woodley DT, Hashimoto T, Amagai $\mathrm{M}$, et al. Induction of keratinocyte IL-8 expression and secretion by IgG autoantibodies as a novel mechanism of epidermal neutrophil recruitment in a pemphigus variant. Clin Exp Immunol. (2000) 119:21724. doi: 10.1046/j.1365-2249.2000.01104.x

29. Albanesi C, Scarponi C, Giustizieri ML, Girolomoni G. Keratinocytes in inflammatory skin diseases. Curr Drug Targets Inflamm Allergy. (2005) 4:329-34. doi: 10.2174/1568010054022033

30. Vasconcellos C, Sotto MN. Experimental cutaneous leishmaniasis: transmission electron microscopy of the inoculation site. Int $J$ Exp Pathol. (1997) 78:81-9. doi: 10.1046/j.1365-2613.1997.d01-243.x

31. Mbow ML, DeKrey GK, Titus RG. Leishmania major induces differential expression of costimulatory molecules on mouse epidermal cells. Eur J Immunol. (2001) 31:14009. doi: 10.1002/1521-4141(200105)31:5<1400::AID-IMMU1400>3.0.CO;2J

32. Scorza BM, Wacker MA, Messingham K, Kim P, Klingelhutz A, Fairley J, et al. Differential activation of human keratinocytes by Leishmania species causing localized or disseminated disease. J Invest Dermatol. (2017) 137:214956. doi: 10.1016/j.jid.2017.05.028

33. Ronet C, Passelli K, Charmoy M, Scarpellino L, Myburgh E, Hauyon La Torre Y, et al. TLR2 signaling in skin nonhematopoietic cells induces early neutrophil recruitment in response to Leishmania major infection. J Invest Dermatol. (2019) 139:1318-28. doi: 10.1016/j.jid.2018.12.012

34. Ehrchen JM, Roebrock K, Foell D, Nippe N, von Stebut E, Weiss JM, et al. Keratinocytes determine Th1 immunity during early experimental leishmaniasis. PLoS Pathog. (2010) 6:e1000871. doi: 10.1371/journal.ppat.1000871

35. Gasim S, Elhassan AM, Khalil EA, Ismail A, Kadaru AM, Kharazmi A, et al. High levels of plasma IL-10 and expression of IL-10 by keratinocytes during visceral leishmaniasis predict subsequent development of post-kala-azar dermal leishmaniasis. Clin Exp Immunol. (1998) 111:649. doi: 10.1046/j.1365-2249.1998.00468.x

36. Eidsmo L, Nylen S, Khamesipour A, Hedblad MA, Chiodi F, Akuffo H. The contribution of the Fas/FasL apoptotic pathway in ulcer formation during Leishmania major-induced cutaneous leishmaniasis. Am J Pathol. (2005) 166:1099-108. doi: 10.1016/S0002-9440(10)62330-9

37. Eidsmo L, Fluur C, Rethi B, Eriksson Ygberg S, Ruffin N, De Milito A, et al. FasL and TRAIL induce epidermal apoptosis and skin ulceration upon exposure to Leishmania major. Am J Pathol. (2007) 170:22739. doi: 10.2353 /ajpath.2007.060068

38. Tasew G, Nylén S, Lieke T, Lemu B, Meless H, Ruffin N, et al. Systemic FasL and TRAIL neutralisation reduce Leishmaniasis induced skin ulceration. PLoS Negl Trop Dis. (2010) 4:e844. doi: 10.1371/journal.pntd.0000844

39. Descatoire M, Hurrell BP, Govender M, Passelli K, Martinez-Salazar B, Hurdayal R, et al. IL-4R $\alpha$ signaling in keratinocytes and early IL-4 production are dispensable for generating a curative T Helper 1 response in Leishmania major-Infected C57BL/6 mice. Front Immunol. (2017) 8:1265. doi: $10.3389 /$ fimmu.2017.01265 
40. Govender M, Hurdayal R, Martinez-Salazar B, Gqada K, Pillay S, Gcanga $\mathrm{L}$, et al. Deletion of interleukin-4 receptor alpha-responsive keratinocytes in $\mathrm{BALB} / \mathrm{c}$ mice does not alter susceptibility to cutaneous leishmaniasis. Infect Immun. (2018) 86:e00710-18. doi: 10.1128/IAI.00710-18

41. Nickoloff BJ, Turka LA. Immunological functions of nonprofessional antigen-presenting cells: new insights from studies of T-cell interactions with keratinocytes. Immunol Today. (1994) 15:464-9. doi: 10.1016/0167-5699(94)90190-2

42. Gaspari AA, Katz SI. Induction of in vivo hyporesponsiveness to contact allergens by hapten-modified Ia+ keratinocytes. I Immunol. (1991) 147:4155-61.

43. Nickoloff BJ, Mitra RS, Green J, Zheng XG, Shimizu Y, Thompson C, et al. Accessory cell function of keratinocytes for superantigens. Dependence on lymphocyte function-associated antigen-1/intercellular adhesion molecule-1 interaction. J Immunol. (1993) 150:2148-59.

44. Black AP, Ardern-Jones MR, Kasprowicz V, Bowness P, Jones L, Bailey AS, et al. Human keratinocyte induction of rapid effector function in antigenspecific memory CD4+ and CD8+ T cells. Eur J Immunol. (2007) 37:148593. doi: 10.1002/eji.200636915

45. Hidalgo A, Chilvers ER, Summers C, Koenderman L. The neutrophil life cycle. Trends Immunol. (2019) 40:584-97. doi: 10.1016/j.it.2019.04.013

46. Mócsai A. Diverse novel functions of neutrophils in immunity, inflammation, and beyond. J Exp Med. (2013) 210:128399. doi: $10.1084 /$ jem.20122220

47. Borregaard N. Neutrophils, from marrow to microbes. Immunity. (2010) 33:657-70. doi: 10.1016/j.immuni.2010.11.011

48. Brinkmann V, Reichard U, Goosmann C, Fauler B, Uhlemann Y, Weiss DS, et al. Neutrophil extracellular traps kill bacteria. Science. (2004) 303:15325. doi: 10.1126/science.1092385

49. Mantovani A, Cassatella MA, Costantini C, Jaillon S. Neutrophils in the activation and regulation of innate and adaptive immunity. Nat Rev Immunol. (2011) 11:519-31. doi: 10.1038/nri3024

50. Schuster S, Hurrell B, Tacchini-Cottier F. Crosstalk between neutrophils and dendritic cells: a context-dependent process. J Leukoc Biol. (2013) 94:6715. doi: 10.1189/jlb.1012540

51. Kolaczkowska E, Kubes P. Neutrophil recruitment and function in health and inflammation. Nat Rev Immunol. (2013) 13:159-75. doi: 10.1038/nri3399

52. Burke VE, Lopez FA. Approach to skin and soft tissue infections in nonHIV immunocompromised hosts. Curr Opin Infect Dis. (2017) 30:35463. doi: 10.1097/QCO.0000000000000378

53. Mortaz E, Alipoor SD, Adcock IM, Mumby S, Koenderman L. Update on neutrophil function in severe inflammation. Front Immunol. (2018) 9:2171. doi: 10.3389/fimmu.2018.02171

54. Marzano AV, Borghi A, Wallach D, Cugno M. A comprehensive review of neutrophilic diseases. Clin Rev Allergy Immunol. (2018) 54:11430. doi: 10.1007/s12016-017-8621-8

55. Marzano AV, Ortega-Loayza AG, Heath M, Morse D, Genovese G, Cugno M. Mechanisms of inflammation in neutrophil-mediated skin diseases. Front Immunol. (2019) 10:1059. doi: 10.3389/fimmu.2019. 01059

56. Phillipson M, Kubes P. The healing power of neutrophils. Trends Immunol. (2019) 40:635-47. doi: 10.1016/j.it.2019.05.001

57. Wong SL, Demers M, Martinod K, Gallant M, Wang Y, Goldfine AB, et al. Diabetes primes neutrophils to undergo NETosis, which impairs wound healing. Nat Med. (2015) 21:815-9. doi: 10.1038/nm.3887

58. Schmitz V, Tavares IF, Pignataro P, Machado AdM, Pacheco FdS, dos Santos JB, et al. Neutrophils in leprosy. Front Immunol. (2019) 10:495. doi: 10.3389/fimmu.2019.00495

59. van Zandbergen G, Hermann N, Laufs H, Solbach W, Laskay T. Leishmania promastigotes release a granulocyte chemotactic factor and induce interleukin- 8 release but inhibit gamma interferon-inducible protein 10 production by neutrophil granulocytes. Infect Immun. (2002) 70:417784. doi: 10.1128/IAI.70.8.4177-4184.2002

60. Peters NC, Egen JG, Secundino N, Debrabant A, Kimblin N, Kamhawi $\mathrm{S}$, et al. In vivo imaging reveals an essential role for neutrophils in leishmaniasis transmitted by sand flies. Science. (2008) 321:9704. doi: $10.1126 /$ science. 1159194
61. Peters NC, Kimblin N, Secundino N, Kamhawi S, Lawyer P, Sacks DL. Vector transmission of Leishmania abrogates vaccine-induced protective immunity. PLoS Pathog. (2009) 5:e1000484. doi: 10.1371/journal.ppat.1000484

62. Dey R, Joshi AB, Oliveira F, Pereira L, Guimarães-Costa AB, Serafim TD, et al. Gut microbes egested during bites of infected sand flies augment severity of leishmaniasis via inflammasome-derived IL-1 $\beta$. Cell Host Microbe. (2018) 23:134-43.e6. doi: 10.1016/j.chom.2017.12.002

63. Teixeira CR, Teixeira MJ, Gomes RBB, Santos CS, Andrade BB, Raffaele-Netto I, et al. Saliva from Lutzomyia longipalpis induces CC chemokine ligand $2 /$ monocyte chemoattractant protein1 expression and macrophage recruitment. J Immunol. (2005) 175:8346-53. doi: 10.4049/jimmunol.175.12.8346

64. de Moura TR, Oliveira F, Rodrigues GC, Carneiro MW, Fukutani KF, Novais FO, et al. Immunity to Lutzomyia intermedia saliva modulates the inflammatory environment induced by Leishmania braziliensis. PLoS Negl Trop Dis. (2010) 4:e712. doi: 10.1371/journal.pntd.0000712

65. Rogers M, Kropf P, Choi B-S, Dillon R, Podinovskaia M, Bates P, et al. Proteophosophoglycans regurgitated by Leishmania-infected sand flies target the L-Arginine metabolism of host macrophages to promote parasite survival. PLoS Pathog. (2009) 5:e1000555. doi: 10.1371/journal.ppat.1000555

66. Beil WJ, Meinardus-Hager G, Neugebauer D-C, Sorg C. Differences in the onset of the inflammatory response to cutaneous leishmaniasis in resistant and susceptible mice. J Leukoc Biol. (1992) 52:135-42. doi: 10.1002/jlb.52.2.135

67. Tacchini-Cottier F, Zweifel C, Belkaid Y, Mukankundiye C, Vasei M, Launois $\mathrm{P}$, et al. An immunomodulatory function for neutrophils during the induction of a CD4+ Th2 response in BALB/c mice infected with Leishmania major. J Immunol. (2000) 165:2628-36. doi: 10.4049/jimmunol.165.5.2628

68. Xin L, Vargas-Inchaustegui DA, Raimer SS, Kelly BC, Hu J, Zhu $\mathrm{L}$, et al. Type I IFN receptor regulates neutrophil functions and innate immunity to Leishmania parasites. J Immunol. (2010) 184:704756. doi: 10.4049/jimmunol.0903273

69. Charmoy M, Brunner-Agten S, Aebischer D, Auderset F, Launois P, Milon G, et al. Neutrophil-derived CCL3 is essential for the rapid recruitment of dendritic cells to the site of Leishmania major inoculation in resistant mice. PLoS Pathog. (2010) 6:e1000755. doi: 10.1371/journal.ppat.1000755

70. Thalhofer CJ, Chen Y, Sudan B, Love-Homan L, Wilson ME. Leukocytes infiltrate the skin and draining lymph nodes in response to the protozoan Leishmania infantum chagasi. Infect Immun. (2011) 79:10817. doi: 10.1128/IAI.00338-10

71. Ribeiro-Gomes FL, Peters NC, Debrabant A, Sacks DL. Efficient capture of infected neutrophils by dendritic cells in the skin inhibits the early anti-Leishmania response. PLoS Pathog. (2012) 8:e1002536. doi: 10.1371/journal.ppat.1002536

72. Sousa LMA, Carneiro MBH, Resende ME, Martins LS, dos Santos LM, Vaz LG, et al. Neutrophils have a protective role during early stages of Leishmania amazonensis infection in BALB/c mice. Parasite Immunol. (2014) 36:13-31. doi: 10.1111/pim.12078

73. Falcão SAC, Weinkopff T, Hurrell BP, Celes FS, Curvelo RP, Prates DB, et al. Exposure to Leishmania braziliensis triggers neutrophil activation and apoptosis. PLoS Negl Trop Dis. (2015) 9:e0003601. doi: 10.1371/journal.pntd.0003601

74. Hurrell BP, Schuster S, Grün E, Coutaz M, Williams RA, Held W, et al. Rapid sequestration of Leishmania mexicana by neutrophils contributes to the development of chronic lesion. PLoS Pathog. (2015) 11:e1004929. doi: 10.1371/journal.ppat.1004929

75. Regli IB, Passelli K, Martínez-Salazar B, Amore J, Hurrell BP, Müller AJ, et al. TLR7 sensing by neutrophils is critical for the control of cutaneous leishmaniasis. Cell Rep. (2020) 31:107746. doi: 10.1016/j.celrep.2020.107746

76. Kimblin N, Peters N, Debrabant A, Secundino N, Egen J, Lawyer P, et al. Quantification of the infectious dose of Leishmania major transmitted to the skin by single sand flies. Proc Natl Acad Sci USA. (2008) 105:1012530. doi: 10.1073/pnas.0802331105

77. Ribeiro-Gomes FL, Roma EH, Carneiro MBH, Doria NA, Sacks DL, Peters NC. Site-dependent recruitment of inflammatory cells determines the effective dose of Leishmania major. Infect Immun. (2014) 82:271327. doi: 10.1128/IAI.01600-13 
78. Chaves MM, Lee SH, Kamenyeva O, Ghosh K, Peters NC, Sacks D. The role of dermis resident macrophages and their interaction with neutrophils in the early establishment of Leishmania major infection transmitted by sand fly bite. PLoS Pathog. (2020) 16:e1008674. doi: 10.1371/journal.ppat.1008674

79. van Zandbergen G, Klinger M, Mueller A, Dannenberg S, Gebert A, Solbach W, et al. Cutting edge: neutrophil granulocyte serves as a vector for Leishmania entry into macrophages. J Immunol. (2004) 173:65215. doi: 10.4049/jimmunol.173.11.6521

80. Ritter U, Frischknecht F, van Zandbergen G. Are neutrophils important host cells for Leishmania parasites? Trends Parasitol. (2009) 25:50510. doi: 10.1016/j.pt.2009.08.003

81. Peniche AG, Bonilla DL, Palma GI, Melby PC, Travi BL, Osorio EY. A secondary wave of neutrophil infiltration causes necrosis and ulceration in lesions of experimental American cutaneous leishmaniasis. PLoS ONE. (2017) 12:e0179084. doi: 10.1371/journal.pone.0179084

82. Charmoy M, Hurrell BP, Romano A, Lee SH, Ribeiro-Gomes F, Riteau N, et al. The Nlrp3 inflammasome, IL-1 $\beta$, and neutrophil recruitment are required for susceptibility to a nonhealing strain of Leishmania major in C57BL/6 mice. Eur J Immunol. (2016) 46:897911. doi: 10.1002/eji.201546015

83. Crosby EJ, Clark M, Novais FO, Wherry EJ, Scott P. Lymphocytic choriomeningitis virus expands a population of NKG2D +CD8+ T cells that exacerbates disease in mice coinfected with Leishmania major. J Immunol. (2015) 195:3301-10. doi: 10.4049/jimmunol.1500855

84. Hurrell BP, Beaumann M, Heyde S, Regli IB, Müller AJ, Tacchini-Cottier F. Frontline science: Leishmania mexicana amastigotes can replicate within neutrophils. J Leukoc Biol. (2017) 102:1187-98. doi: 10.1189/jlb.4HI0417-158R

85. Dabiri S, Hayes MM, Meymandi SS, Basiri M, Soleimani F, Mousavi MR. Cytologic features of "dry-type" cutaneous leishmaniasis. Diagn Cytopathol. (1998) 19:1825. doi: 10.1002/(SICI)1097-0339(199809)19:3 < 182::AID-DC5>3.0.CO;2-F

86. Carlsen ED, Hay C, Henard CA, Popov V, Garg NJ, Soong L. Leishmania amazonensis amastigotes trigger neutrophil activation but resist neutrophil microbicidal mechanisms. Infect Immun. (2013) 81:396674. doi: 10.1128/IAI.00770-13

87. Müller K, van Zandbergen G, Hansen B, Laufs H, Jahnke N, Solbach W, et al. Chemokines, natural killer cells and granulocytes in the early course of Leishmania major infection in mice. Med Microbiol Immunol. (2001) 190:73-6. doi: 10.1007/s004300100084

88. Jacobs T, Andrä J, Gaworski I, Graefe S, Mellenthin K, Krömer M, et al. Complement C3 is required for the progression of cutaneous lesions and neutrophil attraction in Leishmania major infection. Med Microbiol Immunol. (2005) 194:143-9. doi: 10.1007/s00430-004-0229-y

89. Uyttenhove C, Marillier RG, Tacchini-Cottier F, Charmoy M, Caspi RR, Damsker JM, et al. Amine-reactive OVA multimers for auto-vaccination against cytokines and other mediators: perspectives illustrated for GCP-2 in L. major infection. J Leukoc Biol. (2011) 89:1001-7. doi: 10.1189/jlb.1210699

90. Lopez Kostka S, Dinges S, Griewank K, Iwakura Y, Udey MC, von Stebut E. IL-17 promotes progression of cutaneous leishmaniasis in susceptible mice. J Immunol. (2009) 182:3039-46. doi: 10.4049/jimmunol.0713598

91. Laufs H, Müller K, Fleischer J, Reiling N, Jahnke N, Jensenius JC, et al. Intracellular survival of Leishmania major in neutrophil granulocytes after uptake in the absence of Heat-Labile Serum Factors. Infect Immun. (2002) 70:826-35. doi: 10.1128/IAI.70.2.826-835.2002

92. Gueirard P, Laplante A, Rondeau C, Milon G, Desjardins M. Trafficking of Leishmania donovani promastigotes in non-lytic compartments in neutrophils enables the subsequent transfer of parasites to macrophages. Cell Microbiol. (2008) 10:100-11. doi: 10.1111/j.1462-5822.2007.01018.x

93. Guimarães-Costa AB, Nascimento MT, Froment GS, Soares RP, Morgado FN, Conceição-Silva F, et al. Leishmania amazonensis promastigotes induce and are killed by neutrophil extracellular traps. Proc Natl Acad Sci USA. (2009) 106:6748-53. doi: 10.1073/pnas.0900226106

94. Mollinedo F, Janssen H, de la Iglesia-Vicente J, Villa-Pulgarin JA, Calafat J. Selective fusion of azurophilic granules with Leishmania-containing phagosomes in human neutrophils. J Biol Chem. (2010) 285:3452836. doi: 10.1074/jbc.M110.125302
95. Gabriel C, McMaster WR, Girard D, Descoteaux A. Leishmania donovani promastigotes evade the antimicrobial activity of neutrophil extracellular traps. J Immunol. (2010) 185:4319-27. doi: 10.4049/jimmunol.1000893

96. Guimarães-Costa AB, DeSouza-Vieira TS, Paletta-Silva R, Freitas-Mesquita AL, Meyer-Fernandes JR, Saraiva EM. 3'-nucleotidase/nuclease activity allows Leishmania parasites to escape killing by neutrophil extracellular traps. Infect Immun. (2014) 82:1732-40. doi: 10.1128/IAI.01232-13

97. Regli IB, Passelli K, Hurrell BP, Tacchini-Cottier F. Survival mechanisms used by some Leishmania species to escape neutrophil killing. Front Immunol. (2017) 8:1558. doi: 10.3389/fimmu.2017.01558

98. Lima GM, Vallochi AL, Silva UR, Bevilacqua EM, Kiffer MM, Abrahamsohn IA. The role of polymorphonuclear leukocytes in the resistance to cutaneous leishmaniasis. Immunol Lett. (1998) 64:145-51. doi: 10.1016/S0165-2478(98)00099-6

99. Ribeiro-Gomes FL, Otero AC, Gomes NA, Moniz-De-Souza MC, CysneFinkelstein L, Arnholdt AC, et al. Macrophage interactions with neutrophils regulate Leishmania major infection. J Immunol. (2004) 172:445462. doi: 10.4049/jimmunol.172.7.4454

100. Novais FO, Santiago RC, Báfica A, Khouri R, Afonso L, Borges VM, et al. Neutrophils and macrophages cooperate in host resistance against Leishmania braziliensis infection. J Immunol. (2009) 183:808898. doi: 10.4049/jimmunol.0803720

101. Fleming TJ, Fleming ML, Malek TR. Selective expression of Ly-6G on myeloid lineage cells in mouse bone marrow. RB6-8C5 mAb to granulocytedifferentiation antigen (Gr-1) detects members of the Ly-6 family. J Immunol. (1993) 151:2399-408.

102. Lopez AF, Strath M, Sanderson CJ. Differentiation antigens on mouse eosinophils and neutrophils identified by monoclonal antibodies. $\mathrm{Br} J$ Haematol. (1984) 57:489-94. doi: 10.1111/j.1365-2141.1984.tb02923.x

103. Daley JM, Thomay AA, Connolly MD, Reichner JS, Albina JE. Use of Ly6Gspecific monoclonal antibody to deplete neutrophils in mice. J Leukoc Biol. (2008) 83:64-70. doi: 10.1189/jlb.0407247

104. Boivin G, Faget J, Ancey PB, Gkasti A, Mussard J, Engblom C, et al. Durable and controlled depletion of neutrophils in mice. Nat Commun. (2020) 11:2762. doi: 10.1038/s41467-020-16596-9

105. Carneiro $\mathrm{MBH}$, Roma EH, Ranson AJ, Doria NA, Debrabant A, Sacks DL, et al. NOX2-Derived reactive oxygen species control inflammation during Leishmania amazonensis infection by mediating infection-induced neutrophil apoptosis. J Immunol. (2018) 200:196-208. doi: 10.4049/jimmunol.1700899

106. Carmo ÉVdS, Katz S, Barbiéri CL. Neutrophils reduce the parasite burden in Leishmania (Leishmania) amazonensis-infected macrophages. PLoS ONE. (2010) 5:e13815. doi: 10.1371/journal.pone.0013815

107. Carlsen ED, Jie Z, Liang Y, Henard CA, Hay C, Sun J, et al. Interactions between neutrophils and Leishmania braziliensis amastigotes facilitate cell activation and parasite clearance. J Innate Immun. (2015) 7:35463. doi: 10.1159/000373923

108. Smelt SC, Cotterell SE, Engwerda CR, Kaye PM. B cell-deficient mice are highly resistant to Leishmania donovani infection, but develop neutrophil-mediated tissue pathology. J Immunol. (2000) 164:36818. doi: 10.4049/jimmunol.164.7.3681

109. McFarlane E, Perez C, Charmoy M, Allenbach C, Carter KC, Alexander J, et al. Neutrophils contribute to development of a protective immune response during onset of infection with Leishmania donovani. Infect Immun. (2008) 76:532-41. doi: 10.1128/IAI.01388-07

110. Rousseau D, Demartino S, Ferrua B, François Michiels J, Anjuère $\mathrm{F}$, Fragaki $\mathrm{K}$, et al. In vivo involvement of polymorphonuclear neutrophils in Leishmania infantum infection. BMC Microbiol. (2001) 1:17. doi: 10.1186/1471-2180-1-17

111. Sacramento L, Trevelin SC, Nascimento MS, Lima-Jùnior DS, Costa DL, Almeida RP, et al. Toll-like receptor 9 signaling in dendritic cells regulates neutrophil recruitment to inflammatory foci following Leishmania infantum infection. Infect Immun. (2015) 83:4604-16. doi: 10.1128/IAI.00975-15

112. Sacramento LA, da Costa JL, de Lima MHF, Sampaio PA, Almeida RP, Cunha FQ, et al. Toll-Like receptor 2 is required for inflammatory process development during Leishmania infantum infection. Front Microbiol. (2017) 8:262. doi: $10.3389 /$ fmicb.2017.00262 
113. Anderson CF, Mendez S, Sacks DL. Nonhealing infection despite Th1 polarization produced by a strain of Leishmania major in C57BL/6 mice. $J$ Immunol. (2005) 174:2934-41. doi: 10.4049/jimmunol.174.5.2934

114. Pedraza-Zamora CP, Delgado-Domínguez J, Zamora-Chimal J, Becker I. Th17 cells and neutrophils: close collaborators in chronic Leishmania mexicana infections leading to disease severity. Parasite Immunol. (2017) 39. doi: $10.1111 /$ pim. 12420

115. Tavares NM, Araújo-Santos T, Afonso L, Nogueira PM, Lopes UG, Soares RP, et al. Understanding the mechanisms controlling Leishmania amazonensis infection in vitro: the role of LTB4 derived from human neutrophils. J Infect Dis. (2014) 210:656-66. doi: 10.1093/infdis/jiu158

116. Tavares N, Afonso L, Suarez M, Ampuero M, Prates DB, Araújo-Santos T, et al. Degranulating neutrophils promote leukotriene B4 production by infected macrophages to kill Leishmania amazonensis parasites. J Immunol. (2016) 196:1865-73. doi: 10.4049/jimmunol.1502224

117. Navas A, Vargas DA, Freudzon M, McMahon-Pratt D, Saravia NG, Gómez MA. Chronicity of dermal leishmaniasis caused by Leishmania panamensis is associated with parasite-mediated induction of chemokine gene expression. Infect Immun. (2014) 82:2872-80. doi: 10.1128/IAI.01133-13

118. Navas A, Fernández O, Gallego-Marín C, Castro MdM, Rosales-Chilama M, Murillo J, et al. Profiles of local and systemic inflammation in the outcome of treatment of human cutaneous leishmaniasis caused by Leishmania Viannia. Infect Immun. (2020) 88:e00764-19. doi: 10.1128/IAI.00764-19

119. Boaventura VS, Santos CS, Cardoso CR, de Andrade J, Dos Santos WL, Clarêncio J, et al. Human mucosal leishmaniasis: neutrophils infiltrate areas of tissue damage that express high levels of Th17-related cytokines. Eur J Immunol. (2010) 40:2830-6. doi: 10.1002/eji.200940115

120. Morgado FN, Nascimento MTC, Saraiva EM, Oliveira-Ribeiro Cd, Madeira MdF, Costa-Santos Md, et al. Are neutrophil extracellular traps playing a role in the parasite control in active american tegumentary leishmaniasis lesions? PLoS ONE. (2015) 10:e0133063. doi: 10.1371/journal.pone.0133063
121. Conceição J, Davis R, Carneiro PP, Giudice A, Muniz AC, Wilson $\mathrm{ME}$, et al. Characterization of neutrophil function in human cutaneous leishmaniasis caused by Leishmania braziliensis. PLoS Negl Trop Dis. (2016) 10:e004715. doi: 10.1371/journal.pntd.0004715

122. Cardoso T, Bezerra C, Medina LS, Ramasawmy R, Scheriefer A, Bacellar $\mathrm{O}$, et al. Leishmania braziliensis isolated from disseminated leishmaniasis patients downmodulate neutrophil function. Parasite Immunol. (2019) 41:e12620. doi: 10.1111/pim.12620

123. Yizengaw E, Getahun M, Tajebe F, Cruz Cervera E, Adem E, Mesfin G, et al. Visceral leishmaniasis patients display altered composition and maturity of neutrophils as well as impaired neutrophil effector functions. Front Immunol. (2016) 7:517. doi: 10.3389/fimmu.2016.00517

124. Sharma S, Srivastva S, Davis RE, Singh SS, Kumar R, Nylén S, et al. The phenotype of circulating neutrophils during visceral leishmaniasis. Am J Trop Med Hyg. (2017) 97:767-70. doi: 10.4269/ajtmh.16-0722

125. Teixeira CR, Santos CDS, Prates DB, Dos Santos RT, Araújo-Santos T, de Souza-Neto SM, et al. Lutzomyia longipalpis saliva drives Interleukin-17induced neutrophil recruitment favoring Leishmania infantum infection. Front Microbiol. (2018) 9:881. doi: 10.3389/fmicb.2018.00881

Conflict of Interest: The authors declare that the research was conducted in the absence of any commercial or financial relationships that could be construed as a potential conflict of interest.

Copyright (C) 2021 Passelli, Billion and Tacchini-Cottier. This is an open-access article distributed under the terms of the Creative Commons Attribution License (CC BY). The use, distribution or reproduction in other forums is permitted, provided the original author(s) and the copyright owner(s) are credited and that the original publication in this journal is cited, in accordance with accepted academic practice. No use, distribution or reproduction is permitted which does not comply with these terms. 